\title{
Associations Between Acute Conflict and Maternal Care Usage in Egypt: An Uncontrolled Before-and-After Study Using Demographic and Health Survey Data
}

\author{
Saji S. Gopalan ${ }^{1 *}$, Richard J. Silverwood ${ }^{2}$, Omar Salman $^{1}$, Natasha Howard ${ }^{1}$
}

\begin{abstract}
Background: United Nations' (UN) data indicate that conflict-affected low- and middle-income countries (LMICs) contribute considerably to global maternal deaths. Maternal care usage patterns during conflict have not been rigorously quantitatively examined for policy insights. This study analysed associations between acute conflict and maternal services usage and quality in Egypt using reliable secondary data (as conflict-affected settings generally lack reliable primary data).

Methods: An uncontrolled before-and-after study used data from the 2014 Egypt Demographic and Health Survey (EDHS). The 'pre-conflict sample' included births occurring from January 2009 to January 2011. The 'peri-conflict sample' included births from February 2011 to December 2012. The hierarchical nature of demographic and household survey (DHS) data was addressed using multi-level modelling (MLM).

Results: In total, 2569 pre-conflict and 4641 peri-conflict births were reported. After adjusting for socioeconomic variables, conflict did not significantly affect antenatal service usage. Compared to the pre-conflict period, periconflict births had slightly lower odds of delivery in public institutions (odds ratio [OR]: 0.987; 95\% CI: 0.975-0.998; $P<.05$ ), institutional postnatal care (OR: $0.995 ; 95 \%$ CI: $0.98-1.00 ; P=.05$ ), and at least 24 hours post-delivery stay (OR: 0.921; 95\% CI: 0.906-0.935; $P<.01$ ). Peri-conflict births had relatively higher odds of doctor-assisted deliveries (OR: 1.021; 95\% CI: 1.004-1.035; $P<.05$ ), institutional deliveries (OR: 1.022; 95\% CI: 1.00-1.04; $P<.05$ ), private institutional deliveries (OR: 1.035; 95\% CI: 1.017-1.05; $P<.001$ ), and doctor-assisted postnatal care (OR: 1.015; 95\% CI: $1.003-1.027 ; P<.05)$. Sensitivity analysis did not change results significantly.

Conclusion: Maternal care showed limited associations with the acute conflict, generally reflecting pre-conflict usage patterns. Further qualitative and quantitative research could identify the effects of larger conflicts on maternal careseeking and usage, and inform approaches to building health system resilience.

Keywords: Acute Conflict, Maternal Care, Multi-Level Modelling, Egypt

Copyright: @ 2019 The Author(s); Published by Kerman University of Medical Sciences. This is an open-access article distributed under the terms of the Creative Commons Attribution License (http://creativecommons.org/ licenses/by/4.0), which permits unrestricted use, distribution, and reproduction in any medium, provided the original work is properly cited.

Citation: Gopalan SS, Silverwood RJ, Salman O, Howard N. Associations between acute conflict and maternal care usage in Egypt: an uncontrolled before-and-after study using demographic and health survey data. Int J Health Policy Manag. 2019;8(3):158-167. doi:10.15171/ijhpm.2018.107
\end{abstract}

\section{Article History:}

Received: 8 October 2017

Accepted: 28 October 2018

ePublished: 21 November 2018

\section{*Correspondence to:}

Saji S. Gopalan

Email: sajisaraswathyg@gmail.com

\section{Key Messages}

\section{Implications for policy makers}

- Associations between conflict and maternal care were limited and usage generally similar to pre-conflict patterns.

- Any maternal health strategy should consider potential effects of conflict and violence on services, including post-delivery stay, to mitigate disruption to maternal access and usage.

- $\quad$ Ensuring availability of health data in conflict-affected settings would allow quantitative modelling of the effects of larger conflicts on maternal care-seeking, usage, and quality.

Implications for the public

This study demonstrates the applicability of multi-level modelling (MLM) analysis on hierarchical secondary data while exploring associations between conflict and maternal care. Results inspire further research into maternal care provision and usage in conflict-affected settings. Further research is needed on the role of contextual factors driving maternal service usage during conflicts and potential approaches to building health system resilience. 


\section{Background}

Conflicts affect population health and human development adversely. ${ }^{1}$ Currently, 800 million people live in conflictaffected settings globally. ${ }^{2}$ In 2014,40 active armed-conflicts in 46 countries caused 167000 fatalities. ${ }^{2,3}$ Conflict is considered a major barrier to achieving United Nations (UN) Sustainable Development Goals (SDGs), including improved maternal health status. ${ }^{4,5}$ Conflicts in low- and middleincome countries (LMICs) are associated with poor maternal and child health $(\mathrm{MCH})$ outcomes. ${ }^{6}$ For instance, among the 34 LMICs farthest from reaching global MCH targets, 22 are conflict-affected. Conflict-affected settings are considered to contribute a significant share of global maternal and child deaths (about $30 \%$ to $50 \%$ ), though this is a source of ongoing debate. ${ }^{6,7}$

Inadequate maternal care-seeking is considered as a leading cause of poor $\mathrm{MCH}$ indicators in conflict-affected settings. ${ }^{8}$ During conflict, maternal care requires additional attention to emergency obstetric and newborn care along with routine antenatal (ANC) and postnatal (PNC) care visits. ${ }^{6}$ However, conflict-affected countries generally have less than half of the recommended numbers of health-workers or infrastructure necessary to address maternal care. ${ }^{9-11}$ Maternal and child deaths surge during and after conflict, mainly due to physical violence and the breakdown of healthcare delivery systems. ${ }^{10}$ Epidemiological estimates indicate that access to skilled birth attendants and ANC can reduce maternal deaths considerably (eg, by $33 \%$ and $12 \%$ respectively in LMICs), including during conflict. ${ }^{6,12,13}$ Although appropriate maternal care usage has been identified as the most effective means of improving $\mathrm{MCH}$ in conflict-affected settings, evidence on maternal care-seeking and usage patterns remains limited. ${ }^{9}$ Without better evidence on these patterns during conflict, policy and practice responses may not be effective or efficient. ${ }^{6}$

The Middle-East region historically known for persistent conflicts and Egypt is a conflict-prone country in the region. ${ }^{3,14}$ During 2011-2013, Egypt experienced acute conflict as thousands of civilians protested against the government. ${ }^{15}$ Prolonged armed and unarmed protests across the country disrupted governance and civil life. In addition to increased fatalities and injuries, the conflict was expected to weaken economic growth and human development indicators. ${ }^{15}$ Political paralysis damaged public service delivery systems, access to health services, and healthcare-seeking. ${ }^{16}$ The adverse effects of the conflict on health sector continued as there were prolonged health worker strikes as a result of the conflict, leading to disruption of healthcare services. ${ }^{17}$

Due to the inadequacy of existing data, few studies focus on maternal care usage in conflict-affected settings. ${ }^{6}$ While primary data are preferable when undertaking such uncontrolled before and after analyses, collection of primary data is often challenging during conflict. ${ }^{1,18}$ Reliable secondary data, especially a country-wide demographic and household survey (DHS), may be a feasible alternative option. Egypt was chosen for the following 3 reasons: (1) a recent conflict is better for investigating the effects of conflict on maternal care usage and provides fresh evidence, as the nature and trajectory of conflicts change over time; (2) the 2014 Egypt
DHS provides country-wide data on comprehensive maternal care, enabling a before-and-after comparison of the effect of conflict; and (3) analysis of the effect of the Egyptian conflict on the health system and maternal care remains limited. ${ }^{19}$

\section{Objectives}

The aim of this uncontrolled before-and-after study was to examine the association between the acute 2011-2012 Egyptian conflict and maternal care usage and quality, using 2014 Egypt DHS data. Objectives were to estimate: $(i)$ the association of conflict with usage of antenatal, delivery, and postnatal services; and (ii) the association of conflict with quality of antenatal services received.

\section{Methods}

Study Setting

The pluralistic Egyptian healthcare system demonstrates inequities, with rural areas possessing poorer infrastructure, funding, and human resources than urban areas. ${ }^{15,20}$ Private out-of-pocket spending was $72 \%$ of total health spending in 2014 , while total health spending was $5 \%$ of gross domestic product in 2011. ${ }^{21}$ The public sector, despite being the largest healthcare provider, faces constraints such as limited funding, staff, and managerial capacity. ${ }^{16,20,22}$ During the last decade, $\mathrm{MCH}$ scenario in Egypt has been showing some progress with growing inequalities..$^{21}$ In 2012, the under-five mortality rate was 27 per 1000 live births while the maternal mortality ratio was 82 per 100000 live births. ${ }^{19}$ Rural children were more at risk of anaemia than urban children (29\% and $23 \%$ respectively) in 2014. ${ }^{23}$ A hospital-based study in 2009 indicated obstetric haemorrhage, hypertensive disorders of pregnancy and cardiac arrest were major causes of maternal deaths. ${ }^{24}$ Poor quality care and delay in seeking care were also other reasons reported for maternal deaths. ${ }^{24}$

The Egyptian revolution began in January 2011, and its acute phase continued until 2013. ${ }^{15}$ Media reports indicate the country is still at risk of conflicts among different political groups. ${ }^{14}$ The acute phase began when thousands of civilians protested against the Government, led by then long-time president Hosni Mubarak. ${ }^{14,15}$ Despite his resignation, conflicts continued and became widespread under the military regime. When an elected government took office in 2012, protests became more acute. ${ }^{15}$ Contributing factors to the rise of mass protest, included an autocratic government, rising poverty, and inequitable social programmes. ${ }^{14,15}$ Major events related to the revolution is described in Figure.

\section{Study Design}

A quasi-experimental 'uncontrolled before-and-after' design was selected to explore the relationship between conflict and maternal care usage. Uncontrolled before-and-after studies enable assessment of the relationship between 2 events or interventions, when a typical control is not present but a pre-post comparison is possible. ${ }^{25}$ This design enabled comparison of changes in levels of maternal care usage and quality of care before and during acute conflict. Multi-level modelling (MLM) was applied as it enabled exploration of an association between 2 phenomena within DHS data (as DHS 


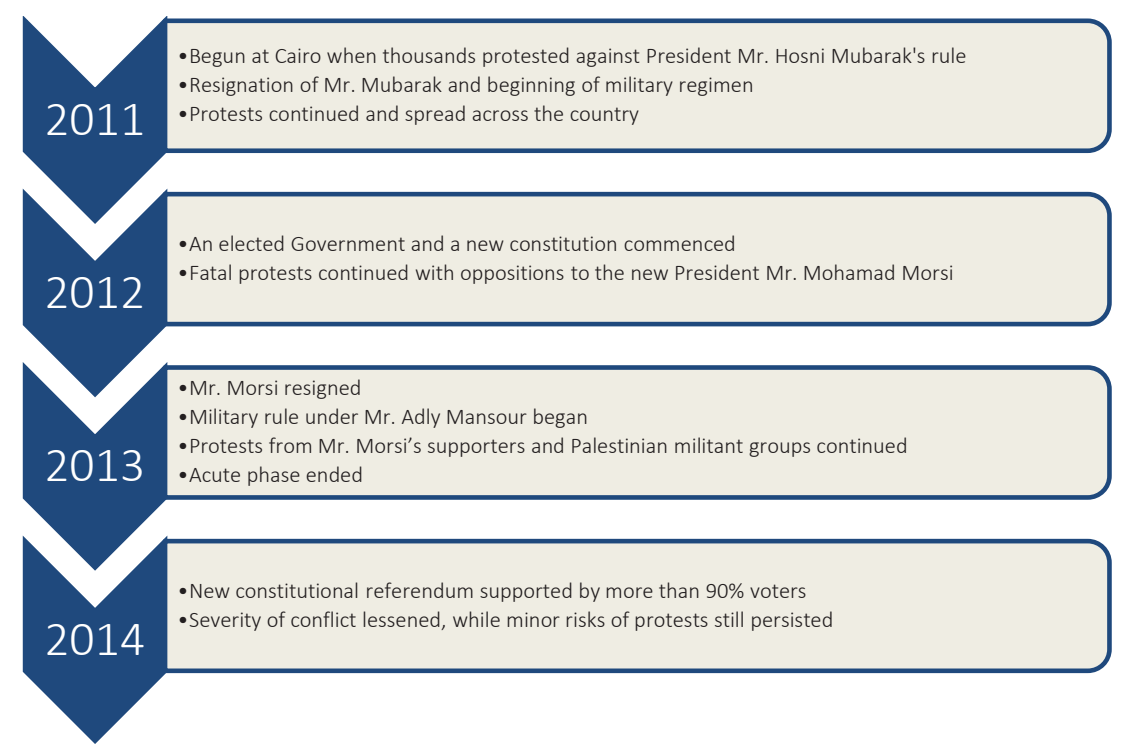

Figure. Major Events Related to Egyptian Conflict 2011. Source: Adapted from Abdou DS ${ }^{15}$ and Maher S. ${ }^{14}$

analysis units are hierarchical), ${ }^{26}$ accounted for the clustered nature of the data, and reduced the chance of type 1 error. ${ }^{27,28}$ Births occurring from January 1, 2009 to January 31, 2011 constituted the 'pre-conflict' sample and those from February 1, 2011 to December 31, 2012 were the 'peri-conflict' sample. While even acute conflicts are rarely 'fixed-period shocks' the way natural disasters can be, authors selected this conflict period in Egypt as multiple data sources indicated it was particularly acute, meaning it could be modelled as a fixed period to examine the effects of conflict on service usage.

The study adopted a working definition of 'conflict-affected' from the relevant literature $\mathrm{e}^{1-3,6,10,18}$ as a setting in which routine socio-political, economic and/or civil life are disrupted due to armed political conflict. Births occurring from January 1 , 2013 onwards were excluded, as media reports indicated that acute conflict ended in early 2013.

Data Source and Sampling

Data were drawn from the Egypt Demographic and Household Survey (EDHS) 2014, ${ }^{19}$ a nationally representative study providing both national and sub-divisional data, though excluding North and South Sinai governorates for political reasons. Authors examined other datasets, eg, ACLED that uses media reports to estimate the spatial distribution of violence, and earlier DHS datasets (eg, 2008 and 2005) to compare violence distribution during conflict and maternal care levels prior to the 'Arab Spring.' However, the 2014 EDHS was determined as most appropriate for robust before-andafter analysis, as other sources did not fit the type of analysis.

EDHS data were collected in April-June 2014. ${ }^{19}$ The EDHS 2014 used multi-stage sampling, with towns and villages as primary sampling units (PSU) for urban and rural areas respectively. ${ }^{19}$ First, 884 PSUs were selected. Second, depending on PSU size, systematic sampling yielded 1-3 parts per PSU (1000 households each). Third, each part was divided into equally-sized segments (200 households each), 2 to 3 of which were selected randomly from each PSU. A total of 1838 segments (clusters) were selected from 884 PSUs. A household listing was undertaken in each segment. An average of 15 households was selected from each segment using a systematic random sample procedure. Thus, yielding a total of 29471 households for the 2014 EDHS. Eligible participants were ever-married women aged 15-49 and present in selected households the night prior to interview. There were a total of 21903 eligible women for the entire survey. From each woman, details on childbirths for the preceding five years from the date of survey were gathered.

Between January 1, 2009 and December 31, 2012, there were 7210 births recorded from 7118 eligible women in 1679 clusters as per EDHS. These 7210 births came from both pre-conflict and peri-conflict periods. Specifically, the preconflict period had 2569 births and the peri-conflict period had 4641 births.

\section{Data Collection and Outcome Measures}

Local enumerators, who were recent university graduates, collected data using an Arabic version of the DHS questionnaire. All questions were pre-tested and revised to suit the local context. This study used the component survey of ever-married women aged 15-49 years, focusing on usage of $\mathrm{MCH}$ services. The questionnaire collected data on respondent background, reproduction, pregnancy and breastfeeding, child immunisation and health, husband's background, and respondent employment and decisionmaking. Maternal care data included location of care-seeking (home, institution), facility type (public, private), provider type (skilled, unskilled), and frequency, timeliness, and content of services received.

Study outcomes were components of maternal care usage, as maternal healthcare is usually categorised by maternity stage, ie, antenatal, delivery, and postnatal (Table 1). Each outcome was analysed by contextual variants, ie, location (facility, non- 
Table 1. Outcome Measures

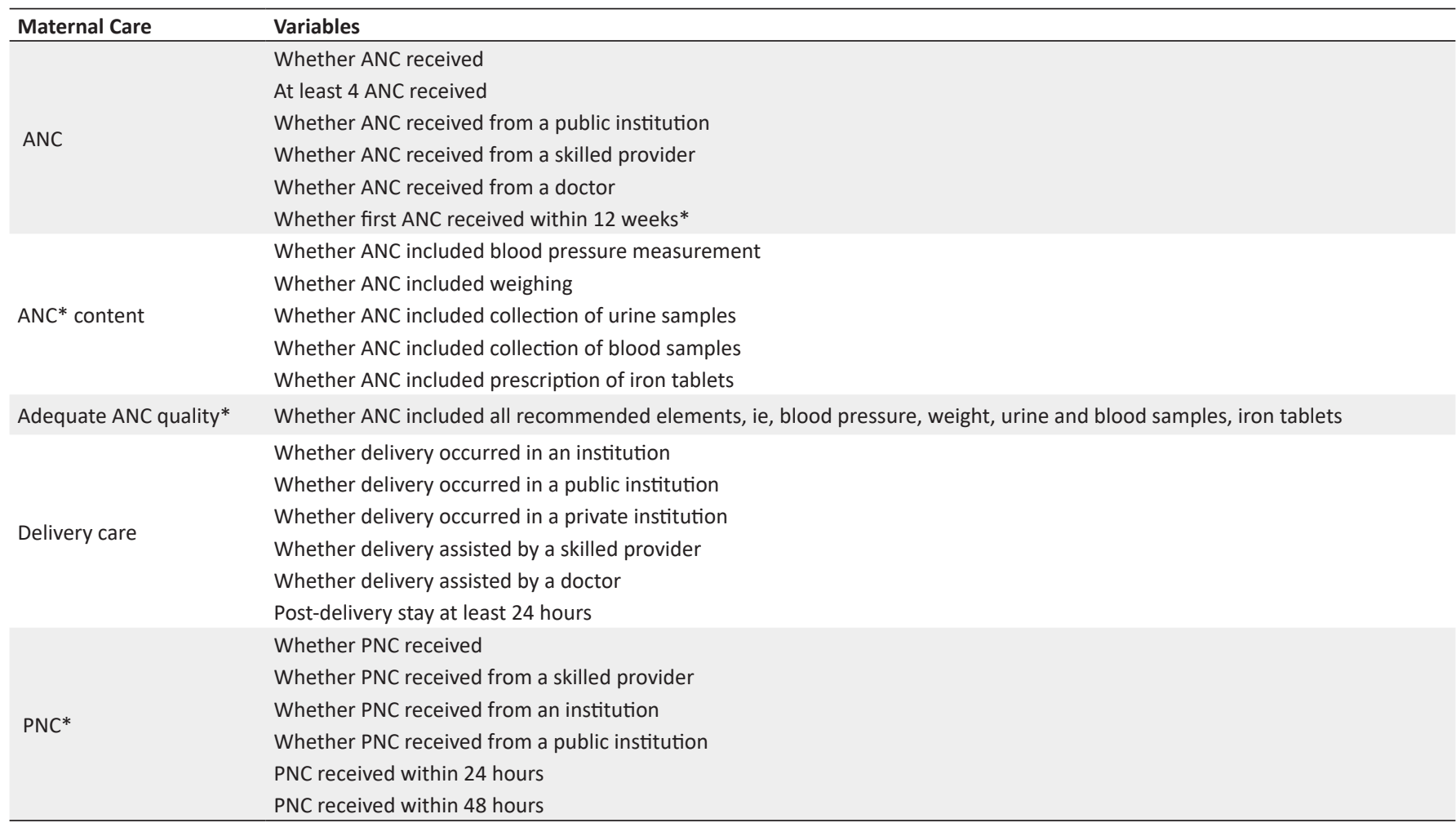

Abbreviations: ANC, antenatal care; PNC, postnatal care.

* Only available for most recent birth.

facility), provider (skilled, unskilled), and number of ANC or PNC visits. Explanatory variables were mother's age $(<25,25-$ $29,30-34,>35$ ), education (no education, primary, secondary and above), occupation (currently working and not working), birth order (1, 2-3, 4-5, 6 and above), child gender, residence (urban/rural), and household wealth quintile.

Wealth quintiles were derived from the EDHS wealth index, which weighted household characteristics and asset possession using principal component analysis (PCA) of their relative importance. ${ }^{19}$ The index categorised sampled households into quintiles from poorest to wealthiest. ANC quality was considered adequate if the woman reported receipt of all five key services: (i) being weighed, (ii) having blood pressure measured, (iii) having a urine sample collected, (iv) having a blood sample collected, and $(v)$ having iron tablets prescribed. This variable was binary, taking value 1 if all services were received and 0 if one or more of these services were not received.

\section{Data Analysis}

Data analysis, performed using Stata version 13, included (i) descriptive analyses; (ii) estimates of effects through MLM; and (iii) sensitivity checks. Descriptive analyses were undertaken on key explanatory variables. Variables were summarised by period (pre-conflict, peri-conflict), using means for continuous variables and frequencies for categorical variables.

$M L M$ analysis enabled investigations of variance within and between clusters, ${ }^{29}$ as EDHS data are hierarchical (ie, births nested within households, households within clusters, clusters within PSUs, PSUs within Governorates). ${ }^{19}$ Conventional regression models do not account for data hierarchy and may underestimate standard errors of the effect sizes, increasing the likelihood of type 1 error. ${ }^{25,29-31}$ Multilevel regression models account for data clustering and correct for the dependency of observations within a cluster (eg, primarily multiple women per household, though multiple births per woman were also accounted for). ${ }^{28,32}$ While a clustered standard errors approach can be more practical, advantages of MLM include that it provides separate estimates for individual states and can address unbalanced data (eg, differing sample sizes in different states). Similarly, fixed effects models can offer improvements for causal estimation by removing potential unobserved confounding at higher levels from parameter estimation, but this also reduces potentially relevant variation. Thus, an MLM or 'random effects' model was selected.

In MLM, the fixed component is a linear function of individual and contextual factors, while the random component represents variance between units within the same level. ${ }^{30,31}$ This analysis considered the sample hierarchy at four levels: births (level 1), nested within clusters (level 2), nested within PSUs (level 3), and nested within governorates (level 4). The study considered women at the same level of analysis as births, since few women had multiple births. ${ }^{19}$

Multilevel logistic regressions were performed adjusting for mother's age, education, residence, employment status, household wealth, child gender, and birth order. Since the DHS applies sampling weights to the sample for national representativeness, these weights were applied in the multilevel regressions. ${ }^{19}$ Sampling weights were rescaled, 
since including raw weights without scaling in an MLM leads to biased parameters and standard errors. ${ }^{31,33}$ In this analysis, weights were scaled so that the new weights summed to the effective cluster size. ${ }^{34}$

The following model specification was used:

$$
\begin{aligned}
& \log \left(\frac{Y_{i j k l}}{1-Y_{i j k l}}\right)= \\
& \alpha+\beta_{1} X_{1 i j k l}+\ldots+\beta_{n} X_{n i j k l}+\gamma T_{i j k l}+ \\
& \theta_{1}+\mu_{k l}+\eta_{j k l}+\varepsilon_{i j k l}
\end{aligned}
$$

Where $\mathrm{Y}_{\mathrm{ijkl}}$ is the binary outcome for birth $\mathrm{i}$ (level 1) within cluster $\mathrm{j}$ (level 2) within PSU k (level 3) within governorate 1 (level 4). $\alpha$ is a constant; $\mathrm{X}_{1 \mathrm{ijkl} \ldots . . . .} \mathrm{X}_{\text {nijkl }}$ are the aforementioned covariates with $\beta_{1} \ldots . . . \beta \mathrm{n}$ as their coefficients; $\mathrm{T}_{\mathrm{ijkl}}$ is a binary variable coded 1 for the peri-conflict period and 0 for the preconflict period, with $\gamma$ as its coefficient; $\theta_{\mathrm{l}}, \mu_{\mathrm{kl}}, \eta_{\mathrm{jkl}}$ and $\varepsilon_{\mathrm{ijkl}}$ are the error terms at governorate, PSU, cluster, and birth levels respectively.

Sensitivity analysis assessed the effects of alterations of study definitions and model specifications in 4 ways. First, varying the cut-off for onset of conflict (January 2011 versus February 2011 versus March 2011). Second, changing levels of analysis (4-level versus 3-level model). Third, applying sampling weights (no weights versus weighted unscaled versus weighted rescaled). Fourth, dropping births that took place closer to conflict onset.

\section{Results}

Sample Characteristics

Table 2 shows the distributions of socioeconomic and demographic variables for 2569 births in the pre-conflict period and 4641 in the peri-conflict period. This unexpected near doubling of births in the peri-conflict period compared to the pre-conflict period was described by the DHS report as due to an unusual national doubling of births from 2011 to early 2014 (eg, total numbers of stillbirths to women aged 15-49 averaged 9783 during 2011-2012 and only 4055 during $2009-2010^{19}$ ). There was a marked shift to younger maternal age between pre-conflict and peri-conflict periods. In the preconflict period $66 \%$ of births were to women aged $30+$ years, but by the peri-conflict period this had declined to $41 \%$. Most births were to women educated to secondary level or above (58.2\% pre-conflict, $61.7 \%$ peri-conflict), living in rural settings (65.1\% pre-conflict, $69.2 \%$ peri-conflict). Slightly above half (55\% pre-conflict and $52.9 \%$ peri-conflict) of births were boys and most mothers already had $2-3$ children $(60.1 \%$ pre-conflict, $54 \%$ peri-conflict). No notable differences were found in wealth status between conflict periods, though most births (23.8\% pre-conflict, $25.1 \%$ peri-conflict) were to women in the middle quintile and non-working women $(84.9 \%$ and $86.7 \%$ respectively). In both periods, approximately $97 \%$ of births were to Muslim women, while the rest were Christian.

\section{Effect of Conflict on Antenatal Service Usage and Quality}

Table 3 shows both unadjusted and adjusted estimates of the

\begin{tabular}{|c|c|c|c|c|}
\hline \multirow[t]{2}{*}{ Characteristics } & \multicolumn{2}{|c|}{$\begin{array}{c}\text { Pre-conflict } \\
n=2569\end{array}$} & \multicolumn{2}{|c|}{$\begin{array}{c}\text { Peri-conflict } \\
n=4641\end{array}$} \\
\hline & No. & $\%$ & No. & $\%$ \\
\hline \multicolumn{5}{|l|}{ Age group } \\
\hline$<25$ & 157 & 6.1 & 1040 & 22.4 \\
\hline $25-29$ & 709 & 27.6 & 1713 & 36.9 \\
\hline $30-34$ & 853 & 33.2 & 1091 & 23.5 \\
\hline$>35$ & 850 & 33.1 & 798 & 17.2 \\
\hline \multicolumn{5}{|l|}{ Education } \\
\hline No education & 550 & 21.4 & 840 & 18.1 \\
\hline Primary & 524 & 20.4 & 937 & 20.2 \\
\hline Secondary and above & 1495 & 58.2 & 2863 & 61.7 \\
\hline \multicolumn{5}{|l|}{ Residence } \\
\hline Urban & 897 & 34.9 & 1429 & 30.8 \\
\hline Rural & 1672 & 65.1 & 3212 & 69.2 \\
\hline \multicolumn{5}{|l|}{ Gender of child } \\
\hline Male & 1413 & 55 & 2455 & 52.9 \\
\hline Female & 1156 & 45 & 2186 & 47.1 \\
\hline \multicolumn{5}{|l|}{ Wealth index } \\
\hline Poorest & 465 & 18.1 & 784 & 16.9 \\
\hline Poorer & 504 & 19.6 & 928 & 20.0 \\
\hline Middle & 611 & 23.8 & 1165 & 25.1 \\
\hline Richer & 516 & 20.1 & 993 & 21.4 \\
\hline Richest & 473 & 18.4 & 770 & 16.6 \\
\hline \multicolumn{5}{|l|}{ Currently working } \\
\hline No & 2181 & 84.9 & 4024 & 86.7 \\
\hline Yes & 388 & 15.1 & 617 & 13.3 \\
\hline \multicolumn{5}{|l|}{ Birth order } \\
\hline 1 & 252 & 9.8 & 1109 & 23.9 \\
\hline $2-3$ & 1544 & 60.1 & 2506 & 54.0 \\
\hline $4-5$ & 622 & 24.2 & 863 & 18.6 \\
\hline 6 and above & 154 & 6.0 & 162 & 3.5 \\
\hline \multicolumn{5}{|l|}{ Religion } \\
\hline Muslim & 2479 & 96.5 & 4488 & 96.7 \\
\hline Christian & 90 & 3.5 & 158 & 3.4 \\
\hline
\end{tabular}
association between conflict and antenatal service usage. After
Table 2. Sample Characteristics for Births

adjusting for socioeconomic (ie, age, education, residence, wealth, working status) and biological determinants (ie, child gender, birth order), no associations between conflict and ANC usage were found.

\section{Effect of Conflict on Delivery Service Usage}

Table 4 shows that the adjusted odds of doctor-assisted deliveries were $2 \%$ higher (odds ratio [OR]: 1.021 ; 95\% CI: 1.004-1.035; $P<.05)$; odds of institutional delivery were $2 \%$ higher (OR: 1.022; 95\% CI: 1.004-1.039; $P<.05$ ); odds of delivering in a private institution were $3 \%$ higher (OR: 1.035; 95\% CI: $1.017-1.053 ; P<.001)$; odds of delivering in a public institution were $1 \%$ lower (OR: 0.987; 95\% CI: 0.975-0.998; $P<.05)$; and odds of a woman's post-delivery stay lasting for at least 24 hours were $8 \%$ lower (OR: 0.921; 95\% CI: 0.906-0.935; 
Table 3. Multilevel Modelling Estimates of the Association of Conflict With ANC Usage and Quality

\begin{tabular}{lcccc}
\hline & \multicolumn{3}{c}{ Means } & \multicolumn{2}{c}{ OR (95\% Cl) } \\
\cline { 2 - 5 } & Pre-conflict & Peri-conflict & Unadjusted & Adjusted $^{\text {a }}$ \\
\hline Any ANC visit & 88.3 & 90.4 & $1.029^{* *}(1.008-1.050)$ & $1.014(0.995-1.033)$ \\
Had 4 or more ANC visits & 92.0 & 92.8 & $1.012^{* *}(1.003-1.020)$ & $1.008(0.996-1.019)$ \\
ANC received from a government provider & 17.4 & 16.4 & $0.987(0.971-1.030)$ & $0.987(0.973-1.001)$ \\
ANC received from a doctor & 61.5 & 62.1 & $1.005(0.978-1.033)$ & $1.006(0.980-1.032)$ \\
First ANC received within 12 weeks & 26.0 & 56.6 & $1.030(0.990-1.060)$ & $1.020(0.990-1.040)$ \\
Weighed during ANC & 90.1 & 89.4 & $0.999(0.981-1.017)$ & $1.000(0.977-1.024)$ \\
Blood pressure measured during ANC & 93.2 & 93.9 & $1.009^{* * *}(1.004-1.014)$ & $1.007(0.997-1.018)$ \\
Urine sample given during ANC & 75.7 & 77.2 & $1.021^{*}(1.002-1.041)$ & $1.005(0.975-1.036)$ \\
Blood sample given during ANC & 77.2 & 79.8 & $1.031^{* * *}(1.019-1.043)$ & $1.020(0.997-1.042)$ \\
Iron tablet received during ANC & 64.0 & 66.6 & $1.039^{* * *}(1.016-1.062)$ & $1.015(0.987-1.044)$ \\
Adequate ANC quality & 49.7 & 53.2 & $1.035^{* * *}(1.012-1.057)$ & $1.022(0.996-1.048)$ \\
\hline
\end{tabular}

Abbreviations: OR, odds ratio; ANC, antenatal care.

${ }^{a}$ Multilevel modelling estimates adjusted for age, education, residence, wealth, working status, child gender and birth order; * <.05; **<.01; ***<.001; sample size - pre-conflict 2569; peri-conflict 4641 .

Table 4. Multilevel Modelling Estimates of Association of Conflict With Delivery Service Usage

\begin{tabular}{|c|c|c|c|c|}
\hline & \multicolumn{2}{|c|}{ Means } & \multicolumn{2}{|c|}{ OR $(95 \% \mathrm{Cl})$} \\
\hline & Pre-conflict & Peri-conflict & Unadjusted & Adjusted $^{\mathrm{a}}$ \\
\hline Delivery by skilled provider & 91.3 & 92.5 & $1.017 *(1.001-1.034)$ & $1.012(0.999-1.024)$ \\
\hline Delivery in an institution & 86.2 & 88.4 & $1.029 * *(1.009-1.05)$ & $1.022 *(1.004-1.039)$ \\
\hline Delivery in a public institution & 28.2 & 26.1 & $0.977 * * *(0.966-0.988)$ & $0.987 *(0.975-0.998)$ \\
\hline Post-delivery stay at least 24 hours & 58.3 & 50.7 & $0.929 * *(0.911-0.948)$ & $0.921 * *(0.906-0.935)$ \\
\hline
\end{tabular}

Abbreviation: OR, odds ratio.

${ }^{a}$ Multilevel modelling estimates adjusted for age, education, residence, wealth, working status, child gender and birth order; *<.05; **<.01; ***<.001; sample size - pre-conflict 2569; peri-conflict 4641.

$P<.01)$ for peri-conflict births compared to pre-conflict births.

\section{Effect of Conflict on Postnatal Service Usage}

Table 5 shows that the adjusted odds of doctor-assisted PNC were $2 \%$ higher (OR: 1.015; 95\% CI: 1.003-1.027; $P<.05$ ) and the odds of receiving PNC from an institution were $1 \%$ lower (OR: 0.9; 95\% CI: 0.98-1.00; $P=.05$ ) for peri-conflict versus pre-conflict births.

Sensitivity Analysis

Sensitivity analyses showed that including alternative study definitions and model specifications did not yield different results from those in the main analysis, except slight variations for a few variables (Supplementary file 1, Table S1). A goodness-of-fit analysis, not shown, demonstrated that models with 4 analysis levels provided a better fit than 3-level models.

\section{Discussion}

Primary Findings

This study is one of the first attempts to use DHS data to quantify the association between conflict and maternal services usage. Given the general lack and low quality of primary data in conflict-affected settings, DHS is perhaps the most reliable current data source to explore associations between conflict and maternal health. ${ }^{19}$ This study identified minor associations, both negative and positive, between the acute 2011-2012 Egyptian conflict and usage of selected maternal services. Overall, maternal services usage during the conflict was not found to be noticeably different from routine usage in Egypt. However, MLM appeared to work well and similar modelling approaches could be applied in more severe conflicts or to examine healthcare usage for other reproductive health issues. As the existing literature assessing the impact of conflict on maternal care is limited, authors compared findings with other studies reporting maternal care levels in conflict-affected settings, despite these generally not being able to attribute any observed changes to conflict. Due to the scarcity of evidence, comparisons were expanded beyond acute to include chronic conflicts.

This study was a unique attempt to assess the association of conflict with post-delivery stay. As optimum post-delivery stay is a pre-requisite to reducing postpartum deaths, its inclusion in maternal care assessment is important. However, its assessment is not common and these findings 
Table 5. Multilevel Modelling Estimates of the Association of Conflict With PNC Service Usage

\begin{tabular}{lccc}
\hline & \multicolumn{2}{c}{ Means } & OR (95\% CI) \\
\cline { 2 - 4 } & Pre-conflict & Peri-conflict & Unadjusted \\
\hline Had any PNC & 32.0 & 33.8 & $1.022^{*}(1.005-1.039)$ \\
PNC received within 24 hours & 24.5 & 24.7 & $1.00(0.969-1.031)$ \\
PNC received within 48 hours & 37.7 & 35.9 & $0.977(0.922-1.036)$ \\
PNC received from a skilled provider & 99.9 & 99.6 & $0.998(0.993-1.003)$ \\
PNC received from a doctor & 96.0 & 96.8 & $1.008(0.994-1.022)$ \\
PNC received in an institution & 97.5 & 97.6 & $0.999(0.993-1.005)$ \\
PNC received in a public institution & 17.7 & 16.6 & $0.987-1.030)$ \\
PNC received in a private institution & 81.7 & 83.0 & $0.987(0.956-1.02)$ \\
\hline
\end{tabular}

Abbreviations: OR, odds ratio; PNC, postnatal care.

${ }^{\text {a }}$ Multilevel modelling estimates adjusted for age, education, residence, wealth, working status, child gender and birth order; *<.05; ** <.01; *** <.001; sample size - pre-conflict 2569; peri-conflict 4641.

may inspire researchers to examine delivery stay in maternal care analyses, especially in conflict-affected settings. Among the negative impacts of conflict was an estimated $8 \%$ lower odds for staying at least 24 hours following delivery during conflict. The average maternity ward stay during conflict was 16 hours (not shown in results), considerably less than the World Health Organization (WHO) recommended minimum of 24 hours for uncomplicated vaginal delivery. ${ }^{35}$ This finding is important as reduced facility stay is known to increase morbidity and mortality risks to both mothers and newborns. ${ }^{35,36}$ Epidemiological evidence indicates that almost $50 \%$ of maternal deaths globally, and $40 \%$ in Egypt, occur within 24 hours after birth. ${ }^{35,37,38}$ The literature postulates that the threat to life of patients and health professionals may shorten delivery stays during acute conflict. ${ }^{39-42}$ In some places, hospitals are at risk of violence and mothers prefer to leave with their babies immediately after delivery. ${ }^{43,44}$ However, we found no literature indicating that the Egyptian conflict threatened the lives of patients and professionals resulting in shorter postpartum stays. Thus, further research is needed to explore possible mediators of the shorter average stay noted.

Findings indicated a slight decline in use of public institutions for delivery during conflict. Relatively lower dependence on public institutions for childbirth was a noticeable recent trend in Egypt, ${ }^{38}$ and the literature is mixed on facility choice for delivery during acute conflicts. ${ }^{45-48}$ It may not be an issue of trust, but rather accessibility and safety when choosing a provider during conflict. ${ }^{49}$ In Egypt, women reported limited capacity in public institutions as a reason for choosing private providers. ${ }^{38}$ Even during conflict, they may have considered that private providers could ensure a safer delivery than their public-sector counterparts.

Findings indicated no association between conflict and ANC usage. The literature shows a mixed trend in ANC service usage during conflict. ${ }^{49-51}$ Provisional facility-based arrangements in Pakistan during acute conflict suggested higher rates of ANC usage and earlier initiation of ANC visits. ${ }^{40}$ Community outreach also enhanced early ANC usage during conflicts in South Asia and Africa. ${ }^{40,49,51}$ Alternatively, during the 2006 Lebanon conflict, women reported delayed initiation of ANC. ${ }^{41}$ A Nepal study reported a decline in early ANC use and numbers of ANC visits during conflict. ${ }^{49}$ Increased policy attention and initiatives to improve ANC quality in Egypt in the last decade have led to gradual improvement in reported adherence to ANC clinical guidelines. ${ }^{38}$ The $2 \%$ increased odds in adequate ANC quality during conflict could be due to this ongoing focus on enhancing ANC quality. As the conflict was not severe in violence or duration, providers would still have been expected to comply with treatment protocols. Other studies indicate that prevailing healthcare quality may not be compromised if conflicts are not severely life-threatening. ${ }^{12,52}$ In contrast, during severe armed conflicts in Afghanistan and Yemen, quality of maternal care worsened drastically, ${ }^{53,54}$ while quality of care in refugee camps was mixed depending on contextual factors. ${ }^{44,52}$

The slight increases in odds of institutional deliveries, doctor-assisted deliveries, and childbirth in private institutions support recent trends in Egypt seen in EDHS findings for 2009-2014. ${ }^{19}$ Even during acute conflict, Egyptian women preferred institutional deliveries, particularly in private institutions. Limited trust in public institutions, especially primary and community-level, was identified as a reason to choose private institutions for delivery. ${ }^{16,21,55}$ This preference would have increased the likelihood of doctorassisted deliveries. ${ }^{23}$ The literature is mixed on delivery location during acute and mild conflicts. Due to poor-quality services, women chose home deliveries during the acute conflict in Lebanon. ${ }^{41}$ Similarly, a study including several sub-Saharan African countries reported reduced skilled birth attendance during conflicts. ${ }^{56}$ A study among Liberian women in Buduburam refugee camp in Ghana showed that reproductive health services were less prioritised, leading to reduced usage of essential maternal services. ${ }^{57}$ However, a Nepal study reported increased skilled birth-attendance and institutional deliveries during conflict. ${ }^{45}$

Findings indicated a slight conflict-associated increase in any PNC usage and doctor-assisted PNC, and a decline in institutional PNC. This decline is most likely related to early post-delivery discharge during conflict. Studies from other settings reported that women preferred to informally consult a community-based health-worker for postpartum health 
concerns. ${ }^{40,58,59}$ Without any perceived need or emergency, they were less likely to seek PNC. ${ }^{58}$ Low PNC usage is typical in conflict-affected settings, unless women access refugee camps. ${ }^{6}$ For example, only $20 \%$ use of any PNC was reported during conflict in Yemen ${ }^{60}$ and only $36 \%$ reported in Palestine due to limited skilled personnel. ${ }^{61}$

\section{Implications}

When analysing pathways of maternal care-seeking during conflict, 3 key drivers are availability of healthcare services, existing maternal care use patterns, and conflict severity. ${ }^{62}$ In the Egyptian context, a reason that larger adverse effects of conflict on maternal care or services usage were not found could be that the conflict was relatively minor and did not significantly challenge the health system. ${ }^{15}$ Secondly, the Egyptian healthcare system was relatively well-developed with reasonable levels of maternal care usage, compared to several other conflict-affected countries globally. ${ }^{16}$ Recent Egyptian health system reforms included countrywide initiatives to improve availability and use of maternal care among different population groups. These helped the country perform well against maternal health targets ${ }^{15}$ and could have contributed to increased resilience, helping retain similar levels of maternal care pre/peri-conflict. Experiences from Nepal similarly indicated that a resilient health system could meet many conflict-related challenges while protecting healthcare for mothers and children. ${ }^{12}$ However, health system resilience is a complex concept. While this interpretation of findings could encourage conflict-prone countries to strengthen health systems to increase resilience, further research is necessary to determine whether and how this may have contributed to findings. While it would be useful to use MLM methods to examine the effects of conflict on maternal services in a more significant conflict, pre/peri-conflict data of sufficient quality were not available at the time of this study to attempt this in countries affected by larger conflicts.

The association of the 2011-2012 Egyptian conflict with health service usage was not well documented. Media reports indicated the conflict did not intentionally disrupt healthcare delivery, though indirect disruptions were likely, and overall damage to governance and economy could have adversely affected both the health system and maternal service use. ${ }^{15}$ Thus, policy and practices designed to strengthen community-facility linkages could increase health system resilience to future shocks. For example, coordination of community-based networks with primary health facilities may help encourage women to access services in a timely manner and bring women to health centres safely. ${ }^{63}$ If mothers feel staying at health facilities post-delivery is risky during acute conflict, trained and supplied community-based networks could monitor the health of mothers and babies to reduce health risks. Community-level support systems and women's groups have helped in meeting maternal health objectives in conflict-affected Myanmar, Pakistan, Sri Lanka, and the Philippines. ${ }^{58,64-66}$ Similarly, local non-governmental organizations (NGOs) in the Middle-East and Southeast Asia have motivated pregnant women to use maternity services. ${ }^{41,67}$
The Egyptian health system devolves authority locally. ${ }^{20}$ Local authorities need adequate autonomy to implement remedial measures addressing maternal care during emergencies. ${ }^{12}$ During other conflicts in the region, national governments have reportedly had limited scope and governance capacity to address maternal needs. ${ }^{4}$ Further, maternal health needs can be addressed more feasible locally than nationally during conflicts, as shown in Myanmar, Nepal, Pakistan, and Palestine. . $^{40,41,49,58,68}$

The main contribution of this study is its unique attempt to use secondary DHS data to quantify associations between conflict and maternal services usage using rigorous MLM methods, and showing that these can be applied to other research questions in similar contexts. Qualitative research is also essential to explore the contextual determinants of service usage and relevant remedial measures in Egypt. Research is also needed to understand how health systems in Egypt and other conflict-prone countries can minimise the risks to maternal health during conflict.

\section{Limitations}

Several potential limitations should be noted, particularly related to secondary data analysis and DHS data specifically. First, primary research would have secured additional relevant data, beyond the scope of the DHS (eg, access to emergency obstetric care). Second, given the country-wide geographical spread of the conflict and lack of data on region-specific exposures, this study considered all women to be equally exposed to conflict and could not differentiate level of exposure to conflict. Third, although conflict continued for a longer period, a shorter study period was selected due to availability of reliable data for this period. Similarly, underlying temporal trends could have affected observed associations, although the period under consideration was too short for a large temporal trend to occur. Fourth, DHS data are susceptible to biases (eg, recall and social desirability) as mothers must recall details of their pregnancy and childbirth experiences over several years, ${ }^{19}$ and its sampling frame is limited to households and thus excludes homeless and institutionalised women. ${ }^{19}$ DHS did not cover North and South Sinai regions due to chronic political instability. Additionally, the unexpected differences in sample size between pre-conflict and peri-conflict periods indicate internal validity must be judged carefully, particularly given this study relied on DHS birth-rate data and assessing validity of DHS data collection and analysis was beyond study scope. ${ }^{69}$ Therefore, study findings can only be generalised to the areas included in analysis. Fifth, as effect sizes were generally small, interpretation of results should be cautious. Finally, qualitative data analysis could help corroborate the influence of contextual factors on maternal care usage. Despite these limitations, this is one of the first attempts to analyse the effect of conflict on maternal services use in Egypt or more generally.

\section{Conclusion}

This study analysed DHS data to estimate the effects of conflict on maternal care usage. Overall, the acute conflict did not appear to have a major impact on maternal care usage 
as maternal care usage patterns during conflict were generally similar to recent trends in the country. This study did not find that conflict significantly affected ANC service use, while small positive associations were found in ANC quality score, institutional delivery, doctor-assisted childbirth, and private institutional attendance for delivery and PNC. This study found slightly reduced odds of post-delivery stay of at least 24 hours, childbirth at public institutions, and institutional PNC usage. Further studies are required to fully assess the effects of conflict on maternal morbidity and mortality, investigate contextual drivers of maternal care usage, and identify potential ways to improve health system resilience to support maternal needs in future conflicts.

\section{Ethical issues}

Not applicable for secondary data analyses.

\section{Competing interests}

Authors declare that they have no competing interests.

\section{Authors' contributions}

SSG, RJS, and NH conceptualised the study. SSG analysed data and drafted the first version. RJS and $\mathrm{NH}$ contributed to interpretation and critical review. All authors approved the version for submission.

\section{Authors' affiliations}

'Department of Global Health and Development, Faculty of Public Health and Policy, London School of Hygiene \& Tropical Medicine, London, UK. ${ }^{2}$ Department of Medical Statistics, Faculty of Epidemiology and Population Health, London School of Hygiene \& Tropical Medicine, London, UK.

Supplementary files

Supplementary file 1 contains Table S1.

\section{References}

1. O'Hare BA, Southall DP. First do no harm: the impact of recent armed conflict on maternal and child health in Sub-Saharan Africa. J R Soc Med.2007;100(12):564-570.doi:10.1177/0141076807100012015

2. International Committee of the Red Cross (ICRC). Health Care in Danger: Making the case. ICRC; 2011. http://www.icrc.org/eng/ resources/documents/publication/p4072.htm

3. International Institute for Strategic Studies (IISS). Armed Conflict Survey. Washington DC; Routledge; 2015.

4. United Nations. Sustainable development and progress in conflictaffected countries. New York: United Nations; 2015.

5. United Nations. Post-MDG Agenda. New York: United Nations; 2012.

6. UNFPA. Protecting Mothers in Risky Situations. New York: UNFPA; 2013.

7. Nordenstedt $\mathrm{H}$, Rosling $\mathrm{H}$. Chasing $60 \%$ of maternal deaths in the post-fact era. Lancet. 2016;388(10054):1864-1865. doi:10.1016/ s0140-6736(16)31793-7

8. D'Aoust O, Guha-Sapir D, Group TWB. Demographic and Health Consequences of Civil Conflict. Washington, DC: World Bank; 2010.

9. United Nations Office on Drugs and Crime (UNODC). Accounting for Security and Justice in the Post-2015 Development Agenda. New York: UNODC; 2013.

10. World Development Report. Conflict, Security, and Development. Washington, DC: World Bank; 2011

11. United Nations. Addressing conflict-related sexual violence: an inventory of peace keeping practice. UN Women; 2010.

12. Devkota B, van Teijlingen ER. Understanding effects of armed conflict on health outcomes: the case of Nepal. Confl Health. 2010;4:20. doi:10.1186/1752-1505-4-20

13. Horton S, Levin C. Cost-Effectiveness of Interventions for Reproductive, Maternal, Neonatal, and Child Health. In: Black $\mathrm{RE}$, Laxminarayan R, Temmerman M, Walker N. Reproductive, Maternal, Newborn, and Child Health: Disease Control Priorities, Third Edition (Volume 2). 2nd ed. Washington DC: The World Bank;
2016. https://globalalliancematernalmentalhealth.org/wp-content/ uploads/2018/03/Bookshelf_NBK361907.pdf.

14. Maher S. The Political Economy of the Egyptian Uprising. Mon Rev. 2011;63(6):32. doi:10.14452/MR-063-06-2011-10_2

15. Abdou DS, Zaazou Z. The Egyptian revolution and socio-economic impact. Topics in Middle Eastern and North African Economies. 2013;15(1):92-115.

16. Devi S. Women's health challenges in post-revolutionary Egypt. Lancet. 2013;381(9879):1705-1706. doi:10.1016/S01406736(13)61060-0

17. Adam M. Health Ministry continues to hold out against doctors' strike - Egypt. Egypt: Independent; 2012. https://www.egyptindependent. $\mathrm{com} /$ health-ministry-continues-hold-out-against-doctors-strike/.

18. Southall DP, O'Hare BA. Empty arms: the effect of the arms trade on mothers and children. BMJ. 2002;325(7378):1457-1461.

19. Ministry of Health and Population, Egypt. Egypt Demographic and Health Survey 2014. Cairo: Ministry of Health and Population; 2015.

20. World Health Organization (WHO). Country cooperation strategy for WHO and Egypt 2010-2014. Cairo: WHO; 2010.

21. The World Bank. A roadmap to achieve social justice in health care in Egypt. Washington DC; World Bank; 2015.

22. The World Bank. Knowledge Brief Egypt. Washington DC: World Bank; 2014.

23. Chiang $\mathrm{C}$, Elshair $\mathrm{IH}$, Kawaguchi $\mathrm{L}$, et al. Improvements in the status of women and increased use of maternal health services in rural Egypt. Nagoya J Med Sci. 2012;74(3-4):233-240.

24. Chiang C, Labeeb SA, Higuchi M, Mohamed AG, Aoyama A. Barriers to the use of basic health services among women in rural southern Egypt (Upper Egypt). Nagoya J Med Sci. 2013;75(3-4):225-231.

25. Grimshaw J, Campbell M, Eccles M, Steen N. Experimental and quasi-experimental designs for evaluating guideline implementation strategies. Fam Pract. 2000;17 Suppl 1:S11-16.

26. Worku AG, Yalew AW, Afework MF. Factors affecting utilization of skilled maternal care in Northwest Ethiopia: a multilevel analysis. BMC Int Health Hum Rights. 2013;13(1):20. doi:10.1186/1472$698 \mathrm{x}-13-20$

27. Leyland $\mathrm{AH}$, Groenewegen PP. Multilevel modelling and public health policy. Scand J Public Health. 2003;31(4):267-274.

28. Raudenbush SW, Bryk AS. Hierarchical Linear Models: Applications and Data Analysis Methods. Sage Publications, Inc; 2002.

29. Pickett KE, Pearl M. Multilevel analyses of neighbourhood socioeconomic context and health outcomes: a critical review. J Epidemiol Community Health. 2001;55(2):111-122.

30. Yebyo H, Alemayehu M, Kahsay A. Why do women deliver at home? Multilevel modeling of Ethiopian National Demographic and Health Survey data. PLoS One. 2015;10(4):e0124718. doi:10.1371/journal. pone. 0124718

31. Carle AC. Fitting multilevel models in complex survey data with design weights: Recommendations. BMC Med Res Methodol. 2009;9:49. doi:10.1186/1471-2288-9-49

32. Kreft I, de Leeuw J. Introducing multivlevel modeling. Thousand Oaks, CA,US: Sage Publications, Inc; 1998. doi:10.4135/9781849209366

33. Asparouhov T, Muthen B. Multilevel Modeling of Complex Survey Data. https://www.statmodel.com/download/SurveyJSM1.pdf. Published 2000.

34. Rabe-Hesketh S, Skrondal A. Multilevel and Longitudinal Modeling Using Stata. 2nd ed. Stata Press; 2008.

35. World Health Organization (WHO). Postnatal Care for Mothers and Newborns: Highlights from the World Health Organization 2013 Guidelines. Geneva: WHO; 2015. http://www.who.int/maternal_ child_adolescent/publications/WHO-MCA-PNC-2014-Briefer_ A4.pdf.

36. Ronsmans C, Graham WJ. Maternal mortality: who, when, where, and why. Lancet. 2006;368(9542):1189-1200. doi:10.1016/s01406736(06)69380-x

37. World Health Organization (WHO). Maternal mortality in 1990-2015: WHO, UNICEF, UNFPA, World Bank Group, and United Nations Population Division Maternal Mortality Estimation Inter-Agency Group. Cairo: WHO; 2015. http://www.who.int/gho/maternal_health/ countries/egy.pdf.

38. Abbas AM, Amin MT, Ali SS, Salem NZ. Maternal mortality: a tertiary 
care hospital experience in Upper Egypt. Int $J$ Reprod Contracept Obstet Gynecol. 2016;5(5):1466-1471. doi:10.18203/2320-1770. ijrcog20161306

39. Haar RJ, Footer KH, Singh S, et al. Measurement of attacks and interferences with health care in conflict: validation of an incident reporting tool for attacks on and interferences with health care in eastern Burma. Confl Health. 2014;8(1):23. doi:10.1186/1752-15058-23

40. Lassi ZS, Aftab W, Ariff S, et al. Impact of service provision platforms on maternal and newborn health in conflict areas and their acceptability in Pakistan: a systematic review. Confl Health. 2015;9(1):25. doi:10.1186/s13031-015-0054-5

41. Kabakian-Khasholian T, Shayboub R, El-Kak F. Seeking maternal care at times of conflict: the case of Lebanon. Health Care Women Int. 2013;34(5):352-362. doi:10.1080/07399332.2012.736570

42. Van Damme W, De Brouwere V, Boelaert M, Van Lerberghe W. Effects of a refugee-assistance programme on host population in Guinea as measured by obstetric interventions. Lancet. 1998;351(9116):1609-1613. doi:10.1016/s0140-6736(97)10348-8

43. Kottegoda S, Samuel K, Emmanuel S. Reproductive health concerns in six conflict-affected areas of Sri Lanka. Reprod Health Matters. 2008;16(31):75-82. doi:10.1016/s0968-8080(08)31359-7

44. Outram Q. 'It's terminal either way': an analysis of armed conflict in liberia, 1989-1996. Rev Afr Polit Econ. 1997;24(73):355-371. doi:10.1080/03056249708704268

45. Bhandari TR, Sarma PS, Kutty VR. Utilization of maternal health care services in post-conflict Nepal. Int J Womens Health. 2015;7:783790. doi:10.2147/ijwh.s90556

46. Philips M, Derderian K. Health in the service of state-building in fragile and conflict affected contexts: an additional challenge in the medical-humanitarian environment. Confl Health. 2015;9:13. doi:10.1186/s13031-015-0039-4

47. Hughes J, Hooley T, Hage S, Ingram G. Implementing the New Deal for Fragile States. Washington, DC: The Brookings Institution; 2014

48. Woodward A, Sondorp E, Witter S, Martineau T. Health systems research in fragile and conflict-affected states: a research agendasetting exercise. Health Res Policy Syst. 2016;14(1):51. doi:10.1186/ s12961-016-0124-1

49. Price JI, Bohara AK. Maternal health care amid political unrest: the effect of armed conflict on antenatal care utilization in Nepal. Health Policy Plan. 2013;28(3):309-319. doi:10.1093/heapol/czs062

50. Bosmans M, Nasser D, Khammash U, Claeys P, Temmerman M. Palestinian women's sexual and reproductive health rights in a longstanding humanitarian crisis. Reprod Health Matters. 2008;16(31):103-111. doi:10.1016/s0968-8080(08)31343-3

51. Jamieson DJ, Meikle SF, Hillis SD, Mtsuko D, Mawji S, Duerr A. An evaluation of poor pregnancy outcomes among Burundian refugees in Tanzania. JAMA. 2000;283(3):397-402.

52. Howard N, Kollie S, Souare $\mathrm{Y}$, et al. Reproductive health services for refugees by refugees in Guinea I: family planning. Confl Health. 2008;2(1):12. doi:10.1186/1752-1505-2-12

53. Rahman L, Rob $U$, Mahmud $R$, et al. A pay-for-performance innovation integrating the quantity and quality of care in maternal, newborn and child health services in Bangladesh: P4P Final Report. Dhaka: Population Council; 2011.

54. Sondorp E, Palmer N, Strong L, Wali A. Afghanistan: Paying NGOs for performance in a postconflict setting. In: Eichler R, Levine R, ed. Performance Incentives for Global Health: Potential and Pitfalls. Washington, DC: Center for Global Development; 2009:139-164.

55. Huntington D, Zaky HH, Shawky S, Fattah FA, El-Hadary E. Impact of a service provider incentive payment scheme on quality of reproductive and child-health services in Egypt. $J$ Health Popul Nutr. 2010;28(3):273-280.

56. Gudrun O, Urdal H, Tollefsen AF, Kotsadam A, Belbo R, Ormhaug $\mathrm{CM}$. Armed conflict and maternal health care Micro-level evidence from Sub-Saharan Africa. San Francisco: American Political Science Association; 2015.

57. Deborah D. Reproductive Health and Repatriation of Refugee Women in Africa: A Case of Liberian Refugee Women on Buduburam Camp. https://escholarship.org/uc/item/6rt9d3vr. Published 2012.

58. Teela KC, Mullany LC, Lee $\mathrm{Cl}$, et al. Community-based delivery of maternal care in conflict-affected areas of eastern Burma: perspectives from lay maternal health workers. Soc Sci Med. 2009;68(7):1332-1340. doi:10.1016/j.socscimed.2009.01.033

59. Gubbins $\mathrm{P}$, de Walque D. Progress and challenges for improving child \& maternal health in a post-conflict setting: the case of South Sudan. Washington, DC: Policy Brief; 2010.

60. Basaleem HO. Women's Reproductive Health Seeking Behavior in Four Districts in Sana'a, Yemen: Quantitative and Qualitative Analysis. J Community Med Health Educ. 2012;2(5):153. doi:10.4172/2161-0711.1000153

61. Dhaher E, Mikolajczyk RT, Maxwell AE, Kramer A. Factors associated with lack of postnatal care among Palestinian women: A cross-sectional study of three clinics in the West Bank. BMC Pregnancy Childbirth. 2008;8(1):26. doi:10.1186/1471-2393-8-26

62. Ranson K, Poletti T, Bornemisza O, Sondorp E. Promoting health equity in conflict-affected fragile states. Geneva: WHO; 2007.

63. Brasington A, Abdelmegeid A, Dwivedi $\mathrm{V}$, et al. Promoting healthy behaviors among Egyptian mothers: a quasi-experimental study of a health communication package delivered by community organizations. PLoS One. 2016;11(3):e0151783. doi:10.1371/ journal.pone. 0151783

64. Varley E. Targeted doctors, missing patients: obstetric health services and sectarian conflict in northern Pakistan. Soc Sci Med. 2010;70(1):61-70. doi:10.1016/j.socscimed.2009.09.028

65. Chong N. Displaced and Disrupted: Closing the Gaps in Maternal Health in Conflicts and Crises. News Security Beat. 2016. https:// www.newsecuritybeat.org/2016/12/displaced-disrupted-closinggaps-maternal-health-conflicts-crises/.

66. IMD. Health in Fragile Environments. https://www.imd.org/ globalassets/publications/insightsimd/docs/62.-icrc-health-infragile-environments---ss-08-12-2016.pdf. Published 2016.

67. Lee RB. Delivering maternal health care services in an internal conflict setting in Maguindanao, Philippines. Reprod Health Matters. 2008;16(31):65-74. doi:10.1016/s0968-8080(08)31346-9

68. ISO. Name change for State of Palestine and other minor corrections. ISO 3166-1 Newsletter VI-14. http://www.iso.org/iso/ iso_3166-1_newsletter_vi-14_name_change_state_of_palestine. pdf. Published 2013

69. Radovich E, El-Shitany A, Sholkamy H, Benova L. Rising up: Fertility trends in Egypt before and after the revolution. PLoS One. 2018;13(1):e0190148. doi:10.1371/journal.pone.0190148 